\title{
A NON-LINEAR HYPERBOLIC EQUATION
}

\author{
ELIANA HENRIQUES de BRITO \\ Instituto de Matemática - UFRJ \\ Caixa Postal 1835, ZC-00 \\ Rio de Janeiro - RJ \\ BRAS IL
}

(Received January 10, 1979)

ABSTRACT. In this paper the following Cauchy problem, in a Hilbert space $\mathrm{H}$, is considered:

$$
\begin{aligned}
& (I+\lambda A) u^{\prime \prime}+A^{2} u+\left[\alpha+M\left(\left|A^{\frac{1}{2}} u\right|^{2}\right)\right] A u=f \\
& u(0)=u_{0} \\
& u^{\prime}(0)=u_{1}
\end{aligned}
$$

$M$ and $f$ are given functions, $A$ an operator in $H$, satisfying convenient hypothesis, $\lambda \geq 0$ and $\alpha$ is a real number.

For $u_{0}$ in the domain of $A$ and $u_{1}$ in the domain of $A^{\frac{1}{2}}$, if $\lambda>0$, and $u_{1}$ in $H$, when $\lambda=0$, a theorem of existence and uniqueness of weak solution is proved. KEY WORDS AND PHRASES. Nonlinear wave Equation, Cauchy Problem, Existence and Uniqueness.

1980 MATHEMATICS SUBJECT CLASSIFICATION CODES. 34620,35 L05. 
1. INTRODUCTION.

The physical origin of the problem here considered lies in the theory of vibrations of an extensible beam of length $l$, whose ends are held a fixed distance apart, hinged or clamped, and is either stretched or compressed by an axial force, taking into account the fact that, during vibration, the elements of a beam perform not only a translatory motion, but also rotate; see Timoshenko [9].

A mathematical model for this problem is an initial-boundary value problem for the non-1inear hyperbolic equation

$$
\frac{\partial^{2} u}{\partial t^{2}}-\lambda \frac{\partial^{4} u}{\partial t^{2} \partial x^{2}}+\frac{\partial^{4} u}{\partial x^{4}}-\left[\alpha+\int_{0}^{l}\left[\frac{\partial u}{\partial s}(s, t)\right]^{2} d s\right] \frac{\partial^{2} u}{\partial x^{2}}=0,
$$

where $u(X, t)$ is the deflection of point $\mathcal{X}$ at time $t, \alpha$ is a real constant, proportional to the axial force acting on the beam when it is constrained to lie along the $x$ axis, and $\lambda$ is a nonnegative constant $\left(y^{\lambda}=0\right.$ means neglecting the rotatory inertia, while $\lambda>0$ means considering it). The non-linearity of the equation is due to considering the extensibility of the beam.

This model, when $\lambda=0$, was treated by Dickey [2], Ball [1] and, in a Hilbert space formulation, by Medeiros [5]. For related problems, see Pohozaev [7], Lions [4], Menzala [6] and Rivera [8].

In this paper, a theorem of existence and uniqueness of weak solution for a Cauchy problem in a Hilbert space $\mathrm{H}$, is proved for the equation

$$
(I+\lambda A) u^{\prime \prime}+A^{2} u+\left[\alpha+M\left(\left|A^{\frac{1}{2}} u\right|^{2}\right)\right] A u=f,
$$

with suitable conditions on the operator $A$ and the given functions $M$ and $f$.

This paper 1s divided in three parts. In Part 1, the theorem is stated and existence of a weak solution is proved. In Part 2, its uniqueness is established. Finally, an application is given, in Part 3, when $\mathrm{H}$ is $\mathrm{L}^{2}(\Omega), \Omega$ a bounded open set with regular boundary in $R^{n}$, and $A$ is the Laplace operator $-\Delta$. 


\section{EXISTENCE OF WEAK SOLUTION.}

Let $\mathrm{H}$ be a real Hilbert space, with inner product $($,$) and norm \|$.

Let $A$ be a linear operator in $H$, with domain $D(A)=V$ dense in $H$. With the graph norm of $\mathrm{A}$, denoted \|\| , i.e.

$$
\|v\|^{2}=|v|^{2}+|A v|^{2} \text {, for } v \text { in } v,
$$

$\mathrm{V}$ is a real Hilbert space and its injection in $\mathrm{H}$ is continuous. We assume this injection compact.

Suppose A self-adjoint and positive, i.e., there is a constant $k>0$ such that

$$
(A v, v) \geq k|v|^{2} \text {, for } v \text { in } v \text {. }
$$

Let $\mathrm{V}^{\prime}$ be the dual of $\mathrm{V}$ and $\left\langle,>\right.$ denote the pairing between $\mathrm{V}^{\prime}$ and $\mathrm{V}$. Identifying $H_{\text {and }} \mathrm{H}^{\prime}$, it follows that $\mathrm{V} \subset \mathrm{H} \subset \mathrm{V}^{\prime}$. Injections being continuous and dense, it is known that, for $h$ in $H$ and $v$ in $V,\langle h, v\rangle=(h, v)$.

$$
\begin{aligned}
& \text { Define } A^{2}: V \rightarrow V^{\prime} \text { by } \\
& \left\langle A^{2} u, v\right\rangle=(A u, A v), \text { for } u, v \text { in } v .
\end{aligned}
$$

It follows that $A^{2}$ is a bounded linear operator from $V$ into $V^{\prime}$.

Let $a(u, v)$ denote the bilinear form in $D\left(A^{\frac{1}{2}}\right)$ associated to $A$, i.e.,

$$
\begin{aligned}
& a(u, v)=\left(A^{\frac{1}{2}} u, A^{\frac{1}{2}} v\right) \text {, for } u, v \text { in } D\left(A^{\frac{1}{2}}\right) \\
& a(u) \text { means } a(u, u) .
\end{aligned}
$$

Given $\lambda \geq 0$, consider in $W=D\left((\lambda A)^{\frac{1}{2}}\right)$ the graph norm of $(\lambda A)^{\frac{1}{2}}$, denoted | $\left.\right|_{\lambda}$, i.e.,

$$
|w|_{\lambda}^{2}=|w|^{2}+\lambda\left|A^{\frac{1}{2}} w\right|^{2} \text {, for } w \text { in } w
$$

Note that $W=H$, if $\lambda=0$, and $W=D\left(A^{\frac{1}{2}}\right)$, if $\lambda>0$; hence $V$ is dense in $W$.

Let $\alpha$ be a real number, $M$ a real $C^{1}$ function, with $M^{\prime}(s) \geq 0$, for $s \geq 0$. Assume the existence of positive constants $m_{0}$ and $m_{1}$ such that $M(s) \geq m_{0}+m_{1} s$, 
for $s \geq 0$. Notice that, should $M$ be the identity function, replacement of $\alpha+s$ by $\left(\alpha-m_{0}\right)+\left(m_{0}+s\right)$, with arbitrary $m_{0}>0$, ensures the fulfilment of the above condition on $M$.

The theorem can now be stated.

THEOREM. Given $\mathrm{f}$ in $\mathrm{L}^{2}(0, \mathrm{~T} ; \mathrm{H}), \mathrm{u}_{0}$ in $\mathrm{V}, \mathrm{u}_{1}$ in $\mathrm{W}$, there is a unique function $u=u(t), 0 \leq t<T$, such that:

a) $u \in L^{\infty}(0, T ; V)$

b) $u^{\prime} \in L^{\infty}(0, T ; W)$

c) $\mathrm{u}$ is a weak solution of

$$
(I+\lambda A) u^{\prime \prime}+A^{2} u+\left[\alpha+M\left(\left|A^{\frac{1}{2}} u\right|^{2}\right)\right] A u=f,
$$

i.e., for every $v$ in $v$, u satisfies in $D^{\prime}(0, T)$ :

$$
\begin{aligned}
& \frac{d}{d t}\left[\left(u^{\prime}(t), v\right)+\lambda a\left(u^{\prime}(t), v\right)\right]+(A u(t), A v)+ \\
& +[\alpha+M(a(u(t)))] a(u(t), v)=(f(t), v),
\end{aligned}
$$

d) The following initial conditions hold:

$$
u(0)=u_{0}, \quad u^{\prime}(0)=u_{1}
$$

Before proving the theorem, some remarks are pertinent.

Equation (2.3a) makes sense, because (a) and (b) above imply that $u, A^{\frac{1}{2}} u$, $\mathrm{Au}, \mathrm{u}^{\prime},(\lambda \mathrm{A})^{\frac{1}{2}} \mathrm{u}^{\prime}$ belong to $\mathrm{L}^{\infty}(0, \mathrm{~T} ; \mathrm{H})$.

Initial condition (2.4a) makes sense, because it is known, (see Lions [3]) that if $u$ and $u^{\prime}$ are in $L^{\infty}(0, T ; H)$, then

$$
\text { u belongs to } \mathrm{C}^{\mathrm{O}}(\mathrm{O}, \mathrm{T} ; \mathrm{H}) \text {, }
$$

Now, initial condition (2.4b) must be understood.

Remember $u^{\prime} \in L^{\infty}(0, T ; W)$ implies that $(I+\lambda A) u^{\prime} \in L^{\infty}\left(0, T ; V^{\prime}\right)$, because

$$
\left\langle(I+\lambda A) u^{\prime}, v\right\rangle=\left(u^{\prime}, v\right)+\lambda a\left(u^{\prime}, v\right) \text {, for } v \text { in } v
$$


From (2.3a), it follows that $(I+\lambda A) u^{\prime \prime} \in L^{2}\left(0, T ; V^{\prime}\right)$. The fact that both $(I+\lambda A) u^{\prime}$ and $(I+\lambda A) u^{\prime \prime}$ belong to $L^{2}\left(0, T ; V^{\prime}\right)$ ensures that

$$
(I+\lambda A) u^{\prime} \in C^{0}\left(0, T ; V^{\prime}\right)
$$

Therefore $(I+\lambda A) u^{\prime}(0)$ is defined. Given $u_{1}$ in $W$, set $(I+\lambda A) u^{\prime}(0)=$ $(I+\lambda A) u_{1}$, in $V^{\prime}$. It follows that $u^{\prime}(0)=u_{1}$, because, it will be proved below,

$$
(I+\lambda A) w=0 \text {, for } w \text { in } w \text {, implies } w=0
$$

Indeed, $V$ being dense in $W$, there is a sequence $\left(v_{j}\right)_{j \in N}$ in $V$ that converges to $w$ in $W$, i.e., as $j \rightarrow \infty$,

$$
\left|w-v_{j}\right|_{\lambda}^{2}=\left|w-v_{j}\right|^{2}+\lambda a\left(w-v_{j}\right) \rightarrow 0
$$

and

$$
0=\left\langle(I+\lambda A) w, v_{j}\right\rangle=\left(w, v_{j}\right)+\lambda a\left(w, v_{j}\right)
$$

tends to

$$
(w, w)+\lambda a(w)=|w|_{\lambda}^{2}
$$

Hence $\mathbf{w}=0$.

Proof of Existence:

It will follow Galerkin method. Suppose, for simplicity, v separable.

Let, then, $\left(w_{j}\right)_{j \in N}$ be a sequence in $V$ such that, for each $m$, the set $\mathrm{w}_{1}, \ldots, \mathrm{w}_{\mathrm{m}}$ is linearly independent and the finite linear combinations of $\mathrm{w}_{1}, \mathrm{w}_{2}, \ldots$ are dense in $V$. Let $V_{m}$ denote the finite subspace of $V$, spanned by $w_{1}, \ldots, w_{m}$.

\section{(i) Approximate Solutions}

Search for $u_{m}(t)=\sum_{j=1}^{m} g_{j m}(t) w_{j}$ in $v_{m}$, such that, for all $v$ in $v_{m}$,

$$
\begin{aligned}
\left((I+\lambda A) u_{m}^{\prime \prime}(t), v\right)+ & \left(A u_{m}(t), A v\right)+\left[\alpha+M\left(a\left(u_{m}(t)\right)\right]\left(A u_{m}(t), v\right)=(f(t), v)\right. \\
& u_{m}(0)=u_{o m}, u_{m}^{\prime}(0)=u_{1 m},
\end{aligned}
$$


where $u_{o m}$ converges to $u_{0}$ in $v$ and $u_{1 m}$ to $u_{1}$ in $w$.

This system of ordinary differential equations with initial conditions has a solution $u_{m}(t)$, defined for $0 \leq t<t_{m} \leq T$. It is convenient to emphasize that the matrix $\left((I+\lambda A) w_{j}, w_{i}\right), i, j=1, \ldots, m$, is invertible, for otherwise the homogeneous system of linear equations

$$
\sum_{j=1}^{m}\left((I+\lambda A) w_{j}, w_{i}\right) x_{j}=0, i=1, \ldots, m,
$$

would have a non-trivial solution $\alpha_{1}, \ldots, \alpha_{m}$, hence

$$
\left|\sum_{j=1}^{m} \alpha_{j} w_{j}\right|_{\lambda}^{2}=\left((I+\lambda A) \sum_{j=1}^{m} \alpha_{j} w_{j}, \sum_{i=1}^{m} \alpha_{i} w_{i}\right)=0,
$$

a contradiction to the linear independence of $w_{1}, \ldots, w_{m}$.

\section{(ii) A Priori Estimates}

For $v=2 u_{m}^{\prime}(t),(2.8)$ becomes :

$$
\begin{aligned}
\frac{d}{d t}\left|u_{m}^{\prime}(t)\right|^{2} & +\lambda \frac{d}{d t} a\left(u_{m}^{\prime}(t)\right)+\frac{d}{d t}\left|A u_{m}(t)\right|^{2}+\alpha \frac{d}{d t} a\left(u_{m}(t)\right)+ \\
& +M\left(a\left(u_{m}(t)\right)\right) \frac{d}{d t} a\left(u_{m}(t)\right)=2\left(f(t), u_{m}^{\prime}(t)\right)
\end{aligned}
$$

Set $\Pi(\sigma)=\int_{0}^{\sigma} M(s) d s$.

We integrate (2.10) from 0 to $t<t_{m}$ and obtain:

$$
\begin{aligned}
\left|u_{m}^{\prime}(t)\right|^{2} & +\lambda a\left(u_{m}^{\prime}(t)\right)+\left|A u_{m}(t)\right|^{2}+\bar{M}\left(a\left(u_{m}(t)\right)\right) \\
& \leq k_{m}+|\alpha| a\left(u_{m}(t)\right)+\int_{0}^{t}\left|u_{m}^{\prime}(s)\right|^{2} d s,
\end{aligned}
$$

where $\mathrm{K}_{\mathrm{m}}=\left|\mathrm{u}_{1 \mathrm{~m}}\right|^{2}+\lambda \mathrm{a}\left(\mathrm{u}_{1 \mathrm{~m}}\right)+\left|\mathrm{Au}_{\mathrm{om}}\right|^{2}+\mathrm{M}\left(\mathrm{a}\left(\mathrm{u}_{\mathrm{om}}\right)\right)+\int_{0}^{\mathrm{T}}|\mathrm{f}(\mathrm{s})|^{2} \mathrm{ds}$.

By choice, $u_{o m}$ and $u_{1 m}$ converge respectively to $u_{0}$ in $v$ and to $u_{1}$ in $W$ (remember that $\left|u_{1 m}\right|_{\lambda}^{2}=\left|u_{1 m}\right|^{2}+\lambda a\left(u_{1 m}\right)$ ). 
Therefore, there is a constant $\mathrm{C}_{0}>0$, independent of $\mathrm{m}$ and greater than $\mathrm{K}_{\mathrm{m}}$ such that (2.11) still holds, with $\mathrm{K}_{\mathrm{m}}$ replaced by $\mathrm{C}_{\mathrm{o}}$.

$$
\begin{aligned}
& \text { Now, } M(s) \geq m_{0}+m_{1} s \text { implies } \bar{M}(\sigma) \geq m_{0} \sigma+\frac{1}{2} \sigma^{2} \\
& \text { For } \sigma=a\left(u_{m}(t)\right), \text { from }(2.11),(2.12) \text { and }|\alpha| \sigma \leq \frac{|\alpha|}{2 m_{1}}+\frac{m_{1}}{2} \sigma^{2}
\end{aligned}
$$

one obtains:

$$
\left|u_{m}^{\prime}(t)\right|^{2}+\lambda a\left(u_{m}^{\prime}(t)\right)+\left|A u_{m}(t)\right|^{2}+m_{o} a\left(u_{m}(t)\right) \leq c+\int_{0}^{t}\left|u_{m}^{\prime}(s)\right|^{2} d s,
$$

where $\mathrm{C}=\mathrm{c}_{0}+\frac{|\alpha|}{2 \mathrm{~m}_{1}}$, a constant independent of $\mathrm{m}$.

In particular,

$$
\left|u_{m}^{\prime}(t)\right|^{2} \leq c+\int_{0}^{t}\left|u_{m}^{\prime}(s)\right|^{2} d s .
$$

Hence, applying Gronwall inequality

$$
\left|u_{m}^{\prime}(t)\right|^{2} \leq c e^{T}
$$

It follows from $(2.13)$ and $(2.14)$ that

$$
\left|u_{m}^{\prime}(t)\right|^{2}+\lambda a\left(u_{m}^{\prime}(t)\right)+\left|A u_{m}(t)\right|^{2}+m_{o} a\left(u_{m}(t)\right) \leq K
$$

where $\mathrm{K}=\mathrm{C}\left(1+\mathrm{Te}^{\mathrm{T}}\right)$, for all $\mathrm{t}$ in $\left[0, \mathrm{t}_{\mathrm{m}}\right]$ and all $\mathrm{m}$.

In particular, as $k\left|u_{m}(t)\right|^{2} \leq a\left(u_{m}(t)\right)$, it follows that $u_{m}(t)$ remains bounded; hence it can be extended to $[0, T]$. Therefore, (2.15) holds, in fact, for all $\mathrm{m}$ and $\mathrm{t}$ in $[0, \mathrm{~T}]$.

\section{(iii) Passage to the Limit}

It follows that there is a sub-sequence of $\left(u_{m}\right)$, still dentoed $\left(u_{m}\right)$, for which, as $\mathrm{m} \rightarrow \infty$, the following is true, in the weak star convergence of $\mathrm{L}^{\infty}(0, \mathrm{~T} ; \mathrm{H})$ :

$$
\begin{aligned}
& \mathrm{u}_{\mathrm{m}} \rightarrow \mathrm{u}, \\
& \mathrm{a}\left(\mathrm{u}_{\mathrm{m}}\right) \rightarrow \mathrm{a}(\mathrm{u}),
\end{aligned}
$$




$$
\begin{aligned}
& \mathrm{Au}_{\mathrm{m}} \rightarrow \mathrm{Au}, \\
& u_{\mathrm{m}}^{\prime} \rightarrow u^{\prime}, \\
& \lambda a\left(u_{m}^{\prime}\right) \rightarrow \lambda a\left(u^{\prime}\right), \\
& \mathrm{M}\left(\mathrm{a}\left(\mathrm{u}_{\mathrm{m}}\right)\right) \mathrm{Au}_{\mathrm{m}} \rightarrow \psi
\end{aligned}
$$

It must still be proved that, in fact

$$
\psi=\mathrm{M}(\mathrm{a}(\mathrm{u})) \mathrm{Au} \text { - }
$$

(2.22) will be shown to follow from the Lemma below, whose proof, here reproduced, was given by J.L. Lions [3] and [4].

LEMMA. The mapping $\mathrm{v} \rightarrow \mathrm{M}(\mathrm{a}(\mathrm{v}))$ Av from $\mathrm{V}$ into $\mathrm{H}$ is monotonic.

PROOF. The function $\bar{M}(\sigma)=\int_{0}^{\sigma} M(s) d s$ is non-decreasing (because $M^{\prime}(\sigma)=$ $M(\sigma) \geq 0$ ) and convex (because $\bar{M}^{\prime \prime}(\sigma)=M^{\prime}(\sigma) \geq 0$ ).

Take

$$
\phi(\mathrm{v})=\overline{\mathrm{M}}(\mathrm{a}(\mathrm{v})) \text {, for } \mathrm{v} \text { in } \mathrm{v}
$$

It is easy to see that $\phi$ has a Gateau derivative,

$$
\phi^{\prime}(\mathrm{v})=2 \mathrm{M}(\mathrm{a}(\mathrm{v})) \mathrm{Av} \text {, for } \mathrm{v} \text { in } \mathrm{v},
$$

and that $\phi$ is convex, i.e., for $0 \leq \rho \leq 1$,

$$
\phi(\rho v+(1-\rho) w) \leq \rho \phi(v)+(1-\rho) \phi(w) \text {, for } v, w \text { in } v \text {. }
$$

This inequality can be written in the form

$$
\frac{\phi(w+\rho(v-w))-\phi(w)}{\rho} \leq \phi(v)-\phi(w)
$$

Passing to the limit, as $\rho \rightarrow 0$ it follows that

$$
\left(\phi^{\prime}(w), v-w\right) \leq \phi(v)-\phi(w)
$$

and, interchanging the roles of $\mathrm{v}$ and $\mathrm{w}$,

$$
\left(\phi^{\prime}(v), w-v\right) \leq \phi(w)-\phi(v)
$$

Adding the two inequalities above, one obtains:

$$
\left(\phi^{\prime}(w)-\phi^{\prime}(v), w-v\right) \geq 0,
$$


This proves the Lemma.

It can now be shown that $(2.22)$ holds.

Indeed, because of the Lemma, for all $v$ in $L^{2}(0, T ; V)$, it is true that

$$
\left.\int_{0}^{T}\left(M\left(a\left(u_{m}\right)\right) A u_{m}-M(a(v)) A v\right), u_{m}-v\right) d t \geq 0
$$

Because $\left(u_{m}\right)$ is bounded in $L^{\infty}(0, T ; V)$ and $\left(u_{m}^{\prime}\right)$ in $L^{\infty}(0, T ; H)$ and the injection of $\mathrm{V}$ in $\mathrm{H}$ is compact, $\left(u_{m}\right)$ can, further, be supposed to converge to $u$ strongly in $L^{2}(0, T ; H)$. Hence, as $m \rightarrow \infty$ :

$$
\int_{0}^{T}(\psi-M(a(v)) A v, u-v) d t \geq 0
$$

Set $u-v=\rho w, \rho \geq 0$, divide the inequality by $\rho$ and let $\rho \rightarrow 0$, to obtain:

$$
\int_{0}^{T}(\psi-M(a(u)) A u, w) d t \geq 0
$$

This holds for all $w$ in $L^{\infty}(0, T ; V)$, hence $\psi=M(a(u)) A u$.

In the following, let $k$ be fixed, $k<m$; take $v$ in $v_{k}$ and let $m \rightarrow \infty$. (2.19) and (2.20) imply that, in $D^{\prime}(0, T)$,

$$
\begin{aligned}
& \frac{d}{d t}\left(u_{m}^{\prime}(t), v\right) \rightarrow \frac{d}{d t}\left(u^{\prime}(t), v\right), \\
& \lambda \frac{d}{d t} a\left(u_{m}^{\prime}(t), v\right) \rightarrow \lambda \frac{d}{d t} a\left(u^{\prime}(t), v\right)
\end{aligned}
$$

Passing to the limit in (2.8), then (2.23) and (2.24), with (2.17), (2.18), (2.21) and (2.22) ensure that

$$
\begin{aligned}
& \frac{d}{d t}\left[\left(u^{\prime}(t), v\right)+\lambda a\left(u^{\prime}(t), v\right)\right]+(A u(t), A v)+ \\
& +[\alpha+M(a(u(t)))] a(u(t), v)=(f(t), v),
\end{aligned}
$$

holds in $D^{\prime}(0, T)$, for all $v$. in $V_{k}$. By density, (2.25) holds in $D^{\prime}(0, T)$, for all $\mathrm{v}$ in $\mathrm{v}$. 
Therefore, $u$ is, indeed, a weak solution of (2.3a).

It must still be shown, in order to complete the proof of existence, that u satisfies $(2.4 \mathrm{ab})$.

\section{(iv) Initial Conditions}

(2.19) means that, for $\mathrm{V}$ in $\mathrm{V}$ and $\theta$ in $\mathrm{C}^{\prime}(0, \mathrm{~T})$ such that $\theta(0)=1$ and $\theta(T)=0$, as $\mathrm{m} \rightarrow \infty$

$$
\int_{0}^{T}\left(u_{m}^{\prime}(t), v\right) \theta(t) d t \rightarrow \int_{0}^{T}\left(u^{\prime}(t), v\right) \theta(t) d t
$$

Because of (2.5) and (2.16), integrating (2.26) by parts, it follows that

$$
\left(u_{o m}, v\right) \rightarrow(u(0), v) \text {, for } v \text { in } v \text {. }
$$

But $u_{\mathrm{om}} \rightarrow \mathrm{u}_{\mathrm{o}}$ in $\mathrm{v}$; hence (2.27) yields

$$
\left(u_{0}, v\right)=(u(0), v) \text {, for } v \text { in } v \text {, i.e., u satisfies }(2.4 a) \text {. }
$$

To show that u satisfies (2.4b), consider equations (2.3b) and (2.8) for $v=w_{j}, j=1,2 \ldots$. It follows, using (2.17)-(2.18), (2.21) and (2.22), that, as $\mathrm{m} \rightarrow \infty$

$$
\frac{d}{d t}\left[\left(u_{m}^{\prime}(t), w_{j}\right)+\lambda a\left(u_{m}^{\prime}(t), w_{j}\right)\right]
$$

converges to $\frac{d}{d t}\left[\left(u^{\prime}(t), w_{j}\right)+\lambda a\left(u^{\prime}(t), w_{j}\right)\right]$ weak star in $L^{\infty}(0, T)$.

(2.28) means that for $v$ in $V, \theta$ in $C^{1}(0, T)$ such that $\theta(0)=1, \theta(T)=0$,

$$
\begin{aligned}
& \int_{0}^{T} \frac{d}{d t}\left[\left(u_{m}^{\prime}(t), w_{j}\right)+\lambda a\left(u_{m}^{\prime}(t), w_{j}\right)\right] \theta(t) d t \\
\rightarrow & \int_{0}^{T} \frac{d}{d t}\left[\left(u^{\prime}(t), w_{j}\right)+\lambda a\left(u^{\prime}(t), w_{j}\right)\right] \theta(t) d t .
\end{aligned}
$$

Because of (2.6), (2.19) and (2.20), integrating (2.29) by parts, it follows that 


$$
\left(u_{1 m^{\prime}}, w_{j}\right)+\lambda a\left(u_{1 m}, w_{j}\right) \rightarrow\left(u^{\prime}(0), w_{j}\right)+\lambda a\left(u^{\prime}(0), w_{j}\right)
$$

But $u_{1 m} \rightarrow u_{1}$ in $W$, hence the left-hand side of (2.30) converges also to $\left(u_{1}, w_{j}\right)+\lambda a\left(u_{1}, w_{j}\right)$. Therefore

$$
\left(u^{\prime}(0), w_{j}\right)+\lambda a\left(u^{\prime}(0), w_{j}\right)=\left(u_{1}, w_{j}\right)+\lambda a\left(u_{1}, w_{j}\right)
$$

As (2.31) holds for $j=1,2, \ldots$, it follows that, in fact, for all $v$ in $v$ :

$$
\left(u^{\prime}(0), v\right)+\lambda a\left(u^{\prime}(0), v\right)=\left(u_{1}, v\right)+\lambda a\left(u_{1}, v\right)
$$

In other words

$$
(I+\lambda A) u^{\prime}(0)=(I+\lambda A) u_{1} \text { in } V^{\prime}
$$

But this implies, (see [6]) $u^{\prime}(0)=u_{1}$; i.e. u satisfies $(2.4 b)$.

\section{UNIQUENESS}

Let $\mathrm{u}$ and $\overline{\mathrm{u}}$ be two solutions of (2.3a) with the same initial conditions (2.4ab). Thus $\mathbf{w}=\mathrm{u}-\overline{\mathrm{u}}$ satisfies

$$
\begin{gathered}
(I+\lambda A) w^{\prime \prime}+A^{2} w+\alpha A w+M(a(u)) w+[M(a(u))-M(a(\bar{u}))] A \bar{u}=0, \\
w(0)=0, \quad w^{\prime}(0)=0 .
\end{gathered}
$$

The standard energy method cannot be used to prove uniqueness, because, while the left-hand side of $(3.1)$ belongs to $\mathrm{L}^{2}\left(0, \mathrm{~T} ; \mathrm{V}^{\prime}\right)$, $\mathrm{u}^{\prime}$ belongs to $\mathrm{L}^{\infty}(0, \mathrm{~T} ; \mathrm{W})$ and not to $L^{\infty}(0, T ; V)$. A modification has to be made; this procedure can be found in Lions [3].

Consider:

and

$$
\begin{aligned}
& z(t)=\left[\begin{array}{ll}
-\int_{t}^{s} w(\xi) d \xi & \text { for } t \leq s \\
0 & \text { for } t>s
\end{array}\right] \\
& w_{1}(t)=\int_{0}^{t} w(\xi) d \xi,
\end{aligned}
$$


Then

$$
\begin{aligned}
& z(t)=w_{1}(t)-w_{1}(s), \\
& z(0)=-w_{1}(s), \\
& z(s)=0
\end{aligned}
$$

and

$$
z^{\prime}(t)=w(t)
$$

As $w \in L^{\infty}(0, T ; V)$, it is clear $\left[\right.$ see (3.3) and (3.8)] that $z$ and $z^{\prime}$ are in $\mathrm{L}^{1}(0, \mathrm{~T} ; \mathrm{V})$. Hence, it follows from (3.1) that

$$
\begin{aligned}
& \int_{0}^{s}<(I+\lambda A) w^{\prime \prime}(t), z(t),>d t+\int_{0}^{s}(A w(t), A z(t)) d t+ \\
& +\alpha \int_{0}^{s}(A w(t), z(t)) d t+\int_{0}^{s} M(a(u(t)))(A w(t), z(t)) d t+ \\
& +\int_{0}^{s}[M(a(u(t)))-M(a(\bar{u}(t)))](A \bar{u}(t), z(t)) d t=0 .
\end{aligned}
$$

But, $[$ see (3.8)]

$$
\begin{aligned}
<(I+\lambda A) w^{\prime \prime}(t), z(t)> & =\frac{d}{d t}\left((I+\lambda A) w^{\prime}(t), z(t)\right)-\left((I+\lambda A) w^{\prime}(t), z^{\prime}(t)\right) \\
& =\frac{d}{d t}\left((I+\lambda A) w^{\prime}(t), z(t)\right)-\frac{1}{2} \frac{d}{d t}((I+\lambda A) w(t), w(t))
\end{aligned}
$$

Therefore, using $(3.2 \mathrm{ab})$ and $(3.7)$, it follows that (remember $|\mathrm{w}|_{\lambda}^{2}=$ $\left.|w|_{\lambda}^{2}+\lambda a(w)\right)$

$$
\int_{0}^{s}<(I+\lambda A) w^{\prime \prime}(t), z(t)>d t=-\frac{1}{2}|w(s)|_{\lambda}^{2} .
$$

Now, $[$ see $(3.8)]$

$$
(A w(t), A z(t))=\left(A z^{\prime}(t), A z(t)\right)=\frac{1}{2} \frac{d}{d t}|A z(t)|^{2}
$$

Thus, $[$ see $(3.6)$ and $(3.7)]$

$$
\int_{0}^{8}(A w(t), A z(t)) d t=-\frac{1}{2}\left|A w_{1}(s)\right|^{2}
$$


As $|w|_{\lambda} \geq|w|,(3.9),(3.10)$ and (3.11) yield

$$
\begin{aligned}
& |w(s)|^{2}+\left|\mathrm{Aw}_{1}(s)\right|^{2} \leq 2|\alpha| \int_{0}^{s}|(w(t), A z(t))| d t \\
& +2 \int_{0}^{S} M(a(u(t)))|(w(t), A z(t))| d t \\
& +2 \int_{0}^{S}|M(a(u(t)))-M(a(\bar{u}(t)))||(\bar{u}(t), A z(t))| d t
\end{aligned}
$$

As $u, \bar{u} \in L^{\infty}(0, T ; V)$ and, for $s \geq 0, M \geq 0$ is a $c^{1}$ function, with $M^{1} \geq 0$, there is a constant $\mathrm{C}>0$ such that

$$
2 \int_{0}^{S} M(a(u(t)))|(w(t), A z(t))| d t \leq 2 C_{0} \int_{0}^{S}|w(t)||A z(t)| d t
$$

And

$$
\begin{aligned}
& 2 \int_{0}^{S} \mid M(a(u(t))-M(a(\bar{u}(t)))||(\bar{u}(t), A z(t)) \mid d t \\
& \leq 2 C_{0} \int_{0}^{S}|a(u(t))-a(\bar{u}(t))||\bar{u}(t)||A z(t)| d t \\
& \leq 2 C_{0}^{2} \int_{0}^{S}|(A(u(t)+\bar{u}(t)), w(t))||A z(t)| d t \\
& \leq 2 C_{0}^{3} \int_{0}^{S}|w(t)||A z(t)| d t
\end{aligned}
$$

Notice that, [see (3.5)]

$$
2|\mathrm{w}(\mathrm{t})||\mathrm{Az}(\mathrm{t})| \leq 2\left[|\mathrm{w}(\mathrm{t})|^{2}+\left|\mathrm{Aw}_{1}(\mathrm{t})\right|^{2}\right]+\left|\mathrm{Aw} \mathrm{w}_{1}(\mathrm{~s})\right|^{2} \text {. }
$$

Hence, it follows from (3.15) that

$$
2|\alpha| \int_{0}^{s}|(w(t), A z(t))| d t \leq 2|\alpha| \int_{0}^{t}\left[|w(t)|^{2}+\left|A w_{1}(t)\right|^{2}\right] d t+|\alpha| s\left|A w_{1}(s)\right|_{2}^{2}(3.16)
$$

Hence (3.13) and (3.15) give 


$$
\begin{aligned}
& 2 \int_{0}^{S} M(\mathrm{a}(\mathrm{u}(\mathrm{t})))|(\mathrm{w}(\mathrm{t}), \mathrm{Az}(\mathrm{t}))| d t \\
& \leq 2 \mathrm{C}_{0} \int_{0}^{S}\left[|\mathrm{w}(\mathrm{t})|^{2}+\left|\mathrm{Aw}_{1}(\mathrm{t})\right|^{2}\right] \mathrm{dt}+\mathrm{C}_{0} \mathrm{~s}\left|\mathrm{Aw}_{1}(\mathrm{~s})\right|^{2}
\end{aligned}
$$

Now (3.14) and (3.15) give

$$
\begin{aligned}
& 2 \int_{0}^{s}|M(a(u(t)))-M(a(\bar{u}(t)))||(\bar{u}(t), A z(t))| d t \\
& \leq 2 C_{0}^{3} \int_{0}^{s}\left[|w(t)|^{2}+\left|A w_{1}(t)\right|^{2}\right] d t+C_{0}^{3} s\left|A w_{1}(s)\right|^{2}
\end{aligned}
$$

It now follows from (3.12), with (3.16) - (3.17) that

$$
|w(s)|^{2}+(1-C s)\left|A w_{1}(s)\right|^{2} \leq 2 C \int_{0}^{s}\left[|w(t)|^{2}+\left|A w_{1}(t)\right|^{2}\right] d t,
$$

where $c=|\alpha|+c_{0}+c_{0}^{3}$.

Take $s_{0}$ such that, for $0 \leq s \leq s_{0}, \frac{1}{2} \leq 1-$ Cs $\leq 1$. Hence (3.19) yields for $0 \leq s \leq s_{0}$ :

$$
|w(s)|^{2}+\frac{1}{2}\left|A w_{1}(s)\right|^{2} \leq 2 c \int_{0}^{s}\left[|w(t)|^{2}+\left|A w_{1}(t)\right|^{2}\right] d t .
$$

A fortiori, for $0 \leq 8 \leq 8_{0}^{\prime}$,

$$
|w(s)|^{2}+\left|A w_{1}(s)\right|^{2} \leq 4 C \int_{0}^{s}\left[|w(t)|^{2}+\left|A w_{1}(t)\right|^{2}\right] d t .
$$

Applying Gronwall inequality, it then follows that

$$
w(s)=0 \text {, for } 0 \leq s \leq s_{0} \text {. }
$$

Similarly, it is proved that $w(s)=0$, for $s_{0} \leq s \leq s_{0}+\tau$, with $\tau>0$. It then follows that, in fact, $w(s)=0$, for $0 \leq s<T$.

The proof of uniqueness is complete. 


\section{APPLICATION}

For $\Omega$ a bounded open set in $\mathrm{R}^{\mathrm{n}}$, with regular boundary, consider

$$
\mathrm{H}=\mathrm{L}^{2}(\Omega), \quad \mathrm{V}=\mathrm{H}_{\mathrm{O}}^{1}(\Omega) \cap \mathrm{H}^{2}(\Omega)
$$

Let $\Delta$ be the Laplace and $\nabla$ the gradient operators in $\mathrm{R}^{\mathrm{n}}$ respectively. Take $A=-\Delta$, hence $A^{\frac{1}{2}}=\nabla$. Hypothesis on A are satisfied. Notice that, in this case, the condition $(A v, v) \geq k|v|^{2}$, for $v$ in $v$, is the Friedrichs - Poincare inequality; the compactness of the injection of $\mathrm{V}$ in $\mathrm{H}$ is the Rellich theorem.

It is clear that

$$
\begin{aligned}
& \mathrm{W}=\mathrm{L}^{2}(\Omega), \text { if } \lambda=0 \\
& \mathrm{~W}=\mathrm{H}^{1}(\Omega), \text { if } \lambda>0
\end{aligned}
$$

Now $($,$) and ||$ are respectively the inner product and the norm in $L^{2}(\Omega)$. Given

$$
\begin{aligned}
& u_{0} \in H_{0}^{1}(\Omega) \quad H^{2}(\Omega) \\
& u_{1} \in L^{2}(\Omega), \text { if } \lambda=0 ; u_{1} \in H^{1}(\Omega), \text { if } \lambda>0, \\
& f \in L^{2}\left(0, T ; L^{2}(\Omega)\right),
\end{aligned}
$$

the theorem proved above ensures existence and uniqueness of weak solution for the non-linear hyperbolic equation

$$
(I-\lambda \Delta) u+\Delta^{2} u-\left[\alpha M\left(|\nabla u|^{2}\right)\right] \Delta u=f,
$$

satisfying $u(0)=u_{0}, u^{\prime}(0)=u_{1}$.

ACKNOWLEDGEMENT. This research was supported by FIMEP and CEPG - UFRJ. Specia1 acknowledgement is due to Professor L.A. Medeiros, who drew my attention to this problem, for his generous help and encouragement.

\section{REFERENCES}

[1] Ball, J.M. Initial Boundary Value Problems for an Extensible Beam, Journal of Functional Analysis and Applications 42, (1973) 61-90. 
[2] Dickey, R.W. Free Vibrations and Dynamic Buckling of the Extensible Beam, J. Math. Ana1. and App1. 29, (1970), 443-454.

[3] Lions, J.L. Quelques Méthodes de Résolution des Problémes aux Limites Non-Lineaires, Dunod, Gauthier-Villars, Paris, 1969.

[4] Lions, J.L. On Some Questions in Boundary Value Problems of Mathematical Physics, Lecture Notes, Instituto de Matemática, Universidade Federal do Rio de Janeiro, 1977.

[5] Medeiros, L.A. On a New Class of Non-Linear Wave Equations, to appear in in Journal of Mathematical Analysis and Applications.

[6] Menzala, G.P. Une Solution d'une Equation Non-Linéaire d'Evolution, C.R. Acad. Sc. Paris, t. 286, (1978), 273-275.

[7] Pohozaev, S.I. On a Class of Quasi Linear Hyperbolic Equations, Mat. USSR Sbornik, 25, (1975) 1, 145-158.

[ 8] Rivera, P.H. On a Non-Linear Hyperbolic Equation in Hilbert Spaces, Anais Acad. Bras. Ciēncias, Vol. 50, No. 2, 1978.

[9] Timoshenko, S. D.H. Young, and W. Weaver. Vibration Problems in Engineering, John Wiley, 1974 . 


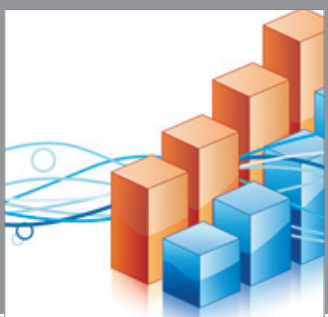

Advances in

Operations Research

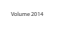

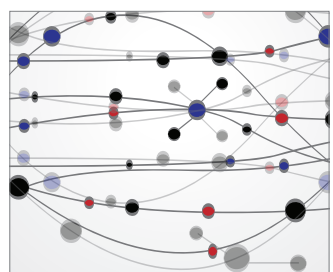

\section{The Scientific} World Journal
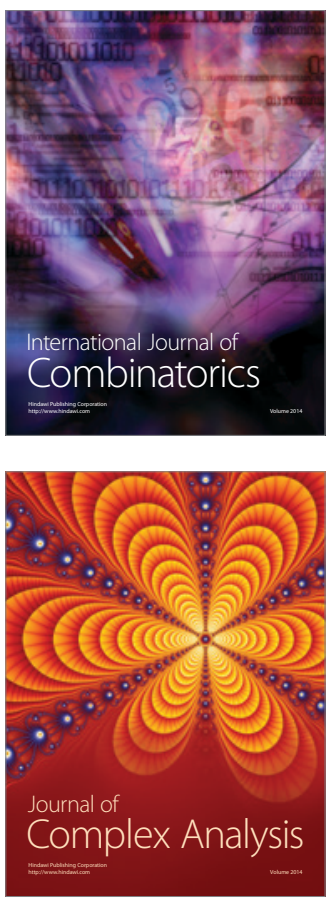

International Journal of

Mathematics and

Mathematical

Sciences
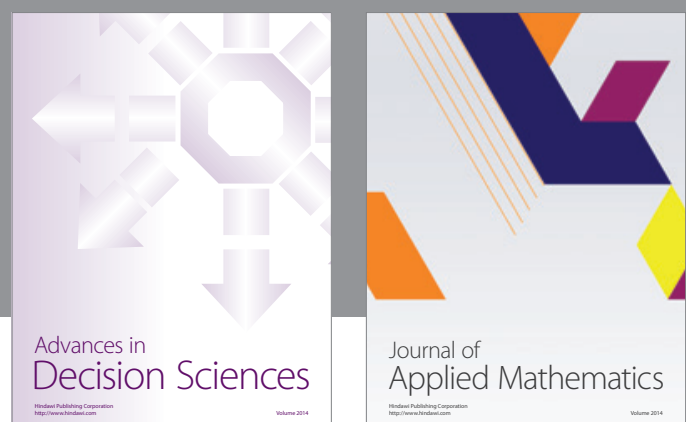

Journal of

Applied Mathematics
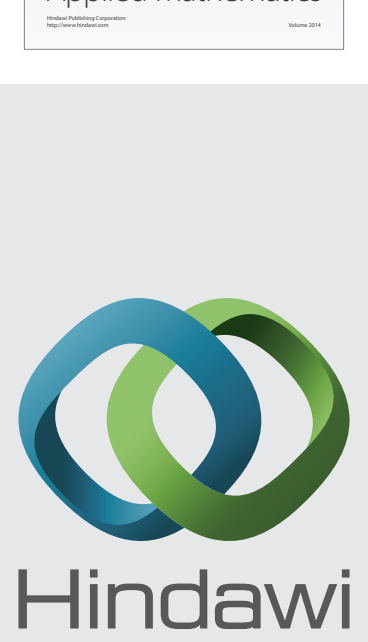

Submit your manuscripts at http://www.hindawi.com
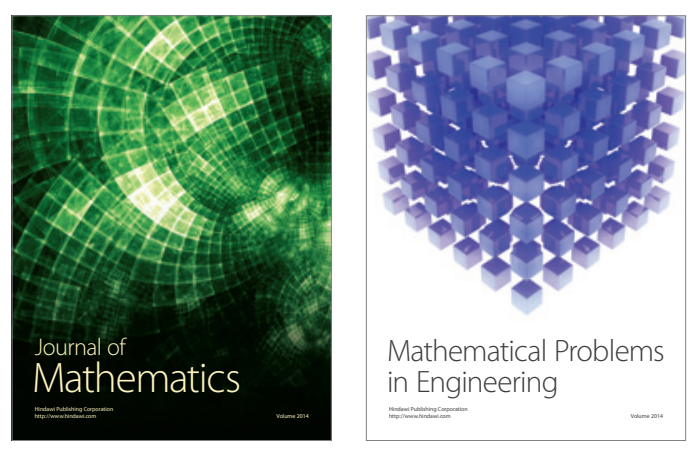

Mathematical Problems in Engineering
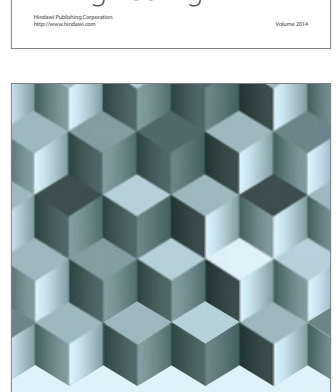

Journal of

Function Spaces
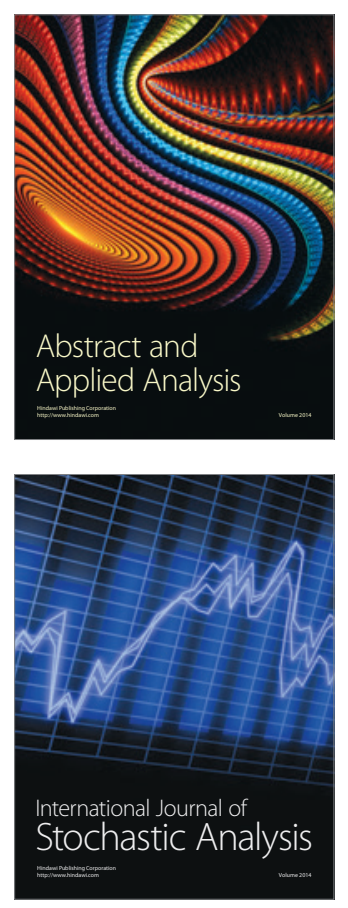

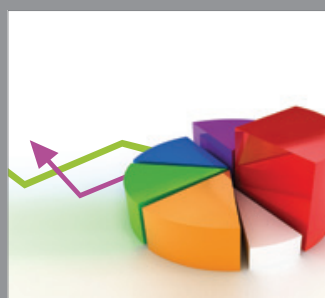

ournal of

Probability and Statistics

Promensencen
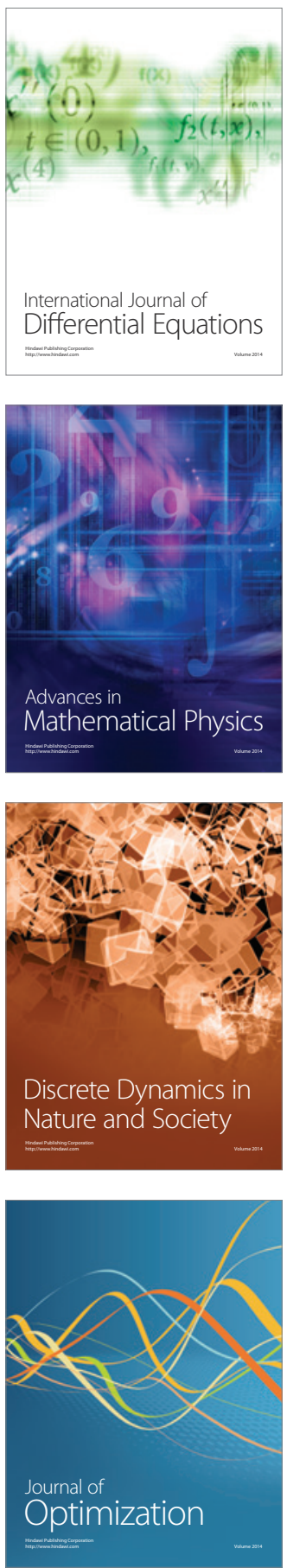